\title{
Metastatic Bone Ewing Sarcoma
}

National Cancer Institute

\section{Source}

National Cancer Institute. Metastatic Bone Ewing Sarcoma. NCI Thesaurus. Code C6621.

An Ewing sarcoma of the bone which has spread from its original site of growth to another anatomic site. 